\title{
CANCIÓN CXXVI DEL CANCIONERO DE PETRARCA
}

Jacobo Cortines

\section{CXXVI}

Chiare, fresche et dolci acque, ove le belle membra

pose colei che sola a me par donna;

gentil ramo ove piacque

(con sospir' mi rimembra)

a lei di fare al bel fiancho colonna;

herba et fior' che la gonna

leggiadra ricoverse

co l'angelico seno;

aere sacro, sereno,

ove Amor co' begli occhi il cor m'aperse:

date udienzia insieme

a le dolenti mie parole extreme.

S'egli è pur mio destino,

e 'l cielo in ciò s'adopra,

ch'Amor quest'occhi lagrimando chiuda,

qualche gratia il meschino

corpo fra voi ricopra,

e torni l'alma al proprio albergo ignuda.

La morte fia men cruda

se questa spene porto

a quel dubbioso passo:

ché lo spirito lasso

non poria mai in piú riposato porto

né in piú tranquilla fossa 
fuggir la carne travagliata et l'ossa.

Tempo verrà anchor forse

ch'a l'usato soggiorno

torni la fera bella et mansüeta,

et là 'v'ella mi scorse

nel benedetto giorno,

volga la vista disiosa et lieta,

cercandomi: et, o pieta!,

già terra in fra le pietre

vedendo, Amor l'inspiri

in guisa che sospiri

sí dolcemente che mercé m'impetre,

et faccia forza al cielo,

asciugandosi gli occhi col bel velo.

Da' be' rami scendea

(dolce ne la memoria)

una pioggia di fior' sovra 'l suo grembo;

et ella si sedea

humile in tanta gloria,

coverta già de l'amoroso nembo.

Qual fior cadea sul lembo,

qual su le treccie bionde,

ch'oro forbito et perle

eran quel dí a vederle;

qual si posava in terra, et qual su l'onde;

qual con un vago errore

girando parea dir: Qui regna Amore.

Quante volte diss'io

allor pien di spavento:

Costei per fermo nacque in paradiso.

Cosí carco d'oblio

il divin portamento

e 'l volto e le parole e 'l dolce riso

m'aveano, et sí diviso

da l'imagine vera,

ch'i' dicea sospirando:

Qui come venn'io, o quando?;

credendo esser in ciel, non là dov'era.

$\mathrm{Da}$ indi in qua mi piace

questa herba sí, ch'altrove non ò pace.

Se tu avessi ornamenti quant'ài voglia, poresti arditamente

uscir del boscho, et gir in fra la gente. 
Claras y dulces aguas, donde los bellos miembros

puso aquella a quien sólo creo señora;

gentil rama en que quiso

(con suspiros me acuerdo)

hallar para su bello flanco apoyo;

hierba y flor que el vestido

gracioso recubriera

con su angélico seno;

sereno aire sagrado,

en el que Amor me hirió con bellos ojos:

escuchad juntamente

mis postreras palabras doloridas.

Si ha de ser mi destino,

y de ello cuida el cielo,

que cierre Amor mis ojos sollozando,

que el cuerpo miserable

halle gracia en vosotros,

y vuelva a su mansión desnuda el alma.

La muerte menos dura

será si así lo espero

en el dudoso paso:

que el espíritu triste

nunca podría en puerto más sereno

ni en más tranquila fosa

escapar de la carne y de los huesos.

Acaso llegue un tiempo

en que al usado sitio

torne la fiera bella y apacible,

y donde me prendiera

aquel bendito día,

vuelva la vista alegre y deseosa,

buscándome, y ¡oh pena!,

ya tierra entre las piedras

viéndome, Amor le inspire

de forma que solloce

tan dulcemente que merced me implore,

y del cielo la obtenga,

secándose los ojos con el velo.

De las ramas caía

(qué dulce en la memoria)

de flores una lluvia en su regazo;

y ella estaba sentada

humilde en tanta gloria, 
por el nimbo amoroso recubierta.

Una cayó en el manto,

otra sobre las trenzas,

que oro pulido y perlas

mostrábanse aquel día;

posábase una en tierra, y otra en agua;

$\mathrm{y}$ alguna en leves giros

parecía decir: Aquí Amor reina.

Cuántas veces yo dije

de miedo lleno entonces:

Esta en verdad nació en el paraíso.

Llenado así de olvido

las divinas maneras,

las palabras, el rostro y dulce risa

me habían, y apartado

de la verdad ya tanto,

que suspirando dije:

¿Cómo llegué aquí, o cuándo?,

creyendo que en el cielo me encontraba.

Y tanto ya amo el prado,

que no encuentro la paz en otro sitio.

Si adornarte supieras cual deseas, con orgullo podrías

salir del bosque, e ir entre la gente. 